\title{
Valproic acid enhances the paclitaxel activity in respiratory tract cancer cells
}

\author{
Ahmed Salim Kadhim Al-Khafaji, ${ }^{1,2}$ Ghaliah Alnefaie, ${ }^{2}$ and Ahmed Majeed Al-Shammari ${ }^{3}$
}

\author{
'Department of Biology, College of Science, University of Baghdad, Baghdad, Iraq. \\ 2Department of Molecular \& Clinical Cancer Medicine, Institute of Translational Medicine University of Liverpool, Liverpool, UK. \\ ${ }^{3}$ Experimental Therapy Department, Iraqi Center for Cancer and Medical, Genetic Research, Mustansiriyah University, Baghdad, Iraq. \\ *Correspondence to Ahmed Salim Kadhim Al-Khafaji (email: khafaji@scbaghdad.edu.iq). \\ (Submitted: 12 April 2019 - Revised version received: 26 April 2019 - Accepted: 21 May 2019 - Published online: 26 August 2019)
}

\begin{abstract}
Objective Epigenetic therapies have already been introduced into clinical cancer management. The main objective of this study is to explore the potential of modulating paclitaxel efficiency using two epigenetic modifiers; valproic acid and decitabin.

Methods The potential sensitisation of lung and oral cancer cells to paclitaxel was examined by two well-known epigenetic modifiers; the DNA methyltransferase inhibitor Decidabine and histone deacetylase class I inhibitor valproic acid (VPA). The effect epigenetic modifiers were tested using qPCR and pyrosequencing techniques utilising respiratory tract cancerous tissues and cell lines.

Results The results exhibited that VPA was an effective epigenetic sensitizer for treating lung and head and neck cancerous cells (A549, SKLU1 and BHY). About $48 \mathrm{~h}$ prior to paclitaxel addition, a significant increase $(\mathrm{p}<0.01)$ of the paclitaxel toxicity was observed when the cancer cells pre-treated with VPA for $48 \mathrm{~h}$ and subsequently with paxlitaxel for $72 \mathrm{~h}$. Interestingly, mRNA expression of AURKA was reduced by VPA treatment. The result also demonstrated that p53 status was involved in VPA-mediated paclitaxel sensitisation of HBEC cell lines to paclitaxel. VPA seems to potentiate p53 wild type cells (HBEC-3KT) to paclitaxel, while p53 HBEC knockouts showed less cytotoxic effect of paclitaxel after exposure to $0.5 \mathrm{mM}$ VPA. On the other hand, decitabin was not efficient to sensitise any of the cell lines to paclitaxel when used in either a synchronous or a preceding manner. In addition, the pyrosequencing analysis of the methylation status of the different gene promoters in the lung tumour and normal tissues showed that all the promoters were unmethylated.

Conclusion It can be concluded that the epigenetic modifier VPA can alter the response of cancer cells to paclitaxel treatment. Further investigation is needed to explore the epigenetic mechanism of sensitising cancerous cells to paclitaxel.

Keywords valproic acid, paclitaxel, lung cancer, head and neck cancer, epigenetic
\end{abstract}

\section{Introduction}

Epigenetic therapies have recently been introduced into clinical cancer management. ${ }^{1,2}$ Previous evidence suggested that valproic acid (VPA) enhances paclitaxel cytotoxic effects in cancerous cells ${ }^{3}$ due to HDAC6 deactivation, which results in tubulin hyperacetylation ${ }^{4}$ and sensitises lung cancer cells to apoptosis. ${ }^{5}$ The combinatory effect of VPA-paclitaxel was also tested in HNSCC tumours. ${ }^{6}$ Aurora kinases also play a transcriptional regulatory role in HDAC inhibitors-mediated cytotoxicity in lung cancer cells. ${ }^{7}$ Recent reported data showed that enhancing p53 acetylation due to HDAC inhibition leads to enhance paclitaxel-induced apoptosis. ${ }^{8}$ In addition, a combination of VPA and decitabin has been introduced in clinical trials to treat NSCLC patients. ${ }^{1,2}$

Epigenetic therapies and epigenetic sensitization of cancer cells to common chemotherapeutics have come to focus in the last decade. ${ }^{9,10}$ As sensitization to taxanes was a major objective of this study, the potential of modulating paclitaxel efficiency was examined using two epigenetic modifiers; valproic acid to induce histone acetylation and decitabin to induce global DNA hypomethylation. Both epigenetic drugs is used as a combination treating patients with lung and head and neck in phase I clinical studies ${ }^{1,2}$ which demonstrated that decreased DNA methylation and induction of histone acetylation were associated with prolonged stable disease for 6 months as a median (4-12 months).

\section{Materials and Methods}

\section{Cell Lines}

NSCLC cell lines (A549 and SK-LU-1), HNSCC cell line (BHY) and HBEC cell lines (HBEC-3KT and HBEC-3KT-53).

\section{Paclitaxel Exposure}

Cells were seeded in 48-well plates in six biological replicates, cultured in $500 \mu \mathrm{L}$ of medium and exposed to increasing concentrations of Paclitaxel (1-35 nM) for $72 \mathrm{~h}$. Growth was measured using the MTT assay.

\section{Primary Lung Tumours}

One hundred and thirty three primary lung tumours [57 adenocarcinomas, 76 squamous cell carcinomas (SqCCL)], and 44 adjacent normal tissues (from 20 adenocarcinoma and 24 SqCCL patients), have been utilised in this study. The mean age of those patients were 67 (45-82). Fifty-six patients were females and 77 males.

\section{RNA Extraction}

Total RNA was extracted from cell lines and primary lung tumours using miRNeasy Mini Kit (QIAGEN), and then quantified by Thermo Scientific NanoDrop 2000 Spectrophotometer.

Reverse Transcription was undertaken using High Capacity cDNA Reverse Transcription Kits (Life Technologies). 


\section{qPCR}

Predesigned Taqman expression assays (Life Technologies) were employed using VIC-labeled ACTB as endogenous control. Real-time PCR assays were performed in triplicate. The genes tested were: AURKA, AURKB, AURKC, CKAP5, TPX2, TTK, KIF11, DLGAP5, TUBB and TUBB3.

\section{DNA Methylation Analysis}

\section{DNA Extraction}

DNA extraction from cell lines and primary lung tumours were performed using DNeasy Blood and Tissue Kit (QIAGEN) using DNeasy 96 protocol for purification of total DNA from tissues and spin-column protocol for purification of total DNA from cell lines.

\section{DNA Methylation}

In order to generate positive control for methylation-specific PCR or bisulfate sequencing, reaction of four units SssI per $\mu \mathrm{g}$ of unmethylated DNA for $2 \mathrm{~h}$ was prepared according the modified manufacturing protocol.

\section{Bisulphite Treatment of DNA}

To investigate the methylation status of the different gene promoters tested in this study, $500 \mathrm{ng}$ DNA from primary tissues was bisulphite treated utilising the EZ-96 DNA Methylation-Gold ${ }^{\text {th }}$ Kit (Zymo Research) following the manufacturer's protocol.

\section{Pyrosequencing Methylation Analysis}

Pyrosequencing (PSQ) is a method that can identify the sequence from small DNAs efficiently and with high fidelity. The samples were prepared for PSQ. The targeted DNA sequence was amplified by PCR using forward biontinylated $(\mathrm{Fb})$, reverse $(\mathrm{R})$ and sequencing $(\mathrm{S})$ primers. The primers were designed by the PyroMark assay design 2.0 software.

\section{Decitabine Efficiency}

This was achieved by pyrosequencing-methylation analysis of the LINE-1.2 (Genebank accession no M80343) retrotransposon (Daskalos 2009). Forward primer: BIO-TAGGGAGTGTTAGATAGTGG, reverse primer: AACTCCCTAACCCCTTAC, sequencing primer: CAAATAAAA CAATACCTC. PCR amplification was performed using QIAGEN HotStarTaq Plus Master Mix Kit.

\section{Statistical Analysis}

The Kolmogorov-Smirnov Test, Mann-Whitney test and Wilcoxon test were employed for statistical analysis using SPSS 20. Bonferroni correction was used to adjust for multiple comparisons. The $\mathrm{IC}_{50}$ values were calculated using GraphPad Prism 5. Kaplan-Meier curves were constructed for survival analysis and the log-rank test was used to examine the differences between groups.

\section{Results}

Based on aforementioned reported data, the epigenetic role of the histone acetylator (VPA) and DNA methylator (decitabin) in sensitising RTC cells to paclitaxel was investigated. The cellular response to VPA was next examined alone in order to select the concentrations below $\mathrm{IC}_{50}$ for further investigation of VPA ability to sensitise cancerous cells to taxanes. MTT analysis of VPA exposure of lung cell lines (A549 and SKLU1) and the second most paclitaxel resistant oral cancer cell line (BHY) demonstrated that these cells are resistant to very high VPA micro-molar concentrations (Fig. 1) with $\mathrm{IC}_{50} \mathrm{~s}$ of 6.63 $\mathrm{mM}$ of A549, $20 \mathrm{mM}$ of SKLU1 and $2.1 \mathrm{mM}$ of BHY) (Table 1) at $95 \% \mathrm{CI}$.

In order to examine the ability of valproate to potentiate the anti-tumour efficacy of paclitaxel in controlling cellular viability, two different doses of valproate 0.5 and $1 \mathrm{mM}$ that are below $\mathrm{IC}_{50} \mathrm{~s}$ of all these three cell lines were used. A fixed dose of paclitaxel $(10 \mathrm{nM})$ was utilised to test our hypothesis. This was also under the $\mathrm{IC}_{50} \mathrm{~s}$ of the examined cell lines; $13.6 \mathrm{nM}$ of A549, $16.7 \mathrm{nM}$ of SKLU1 and $14 \mathrm{nM}$ of BHY. The growth inhibitory effects of $1 \mathrm{mM} \mathrm{VPA}$ and $10 \mathrm{nM}$ paclitaxel were determined as optimal doses utilised either in combination or as successive treatments of the cell lines, A549, SKLU1 and BHY. The synchronous treatment of VPA and paclitaxel produced only a minor additive effect (Data not shown). In contrast, when VPA used to treat the cell for $48 \mathrm{~h}$ prior to paclitaxel addition, a significant increase of the paclitaxel toxicity was observed in the subsequent $72 \mathrm{~h}$ (Fig. 2).

Interestingly, mRNA expression of AURKA in BHY cell line was significantly reduced to around $65 \%$ after treatment with $1 \mathrm{mM}$ VPA for $48 \mathrm{~h}$ (Fig. 3).

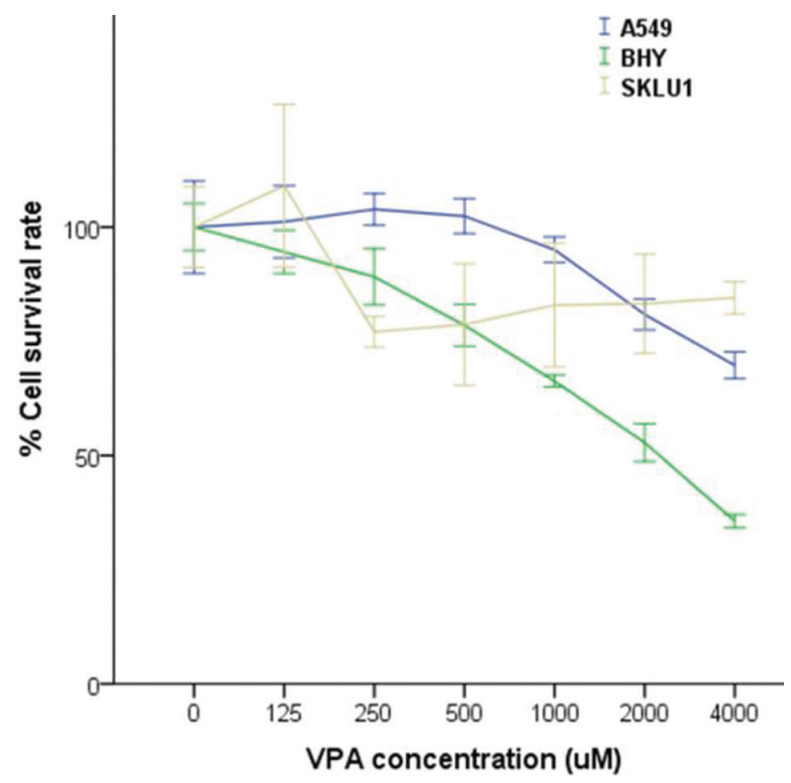

Fig. 1 MTT line graph showing the cellular survival rates of lung (A549 and SKLU1) and HNSCC (BHY) cell lines to VPA. Error bars represent $95 \%$ confidence intervals.

Table 1 The data demonstrating the IC50 values of VPA in A549, SKLU1 and BHY cell lines and their respective $95 \% \mathrm{Cl}$. The results demonstrate that SKLU1 cell line is the most resistant to VPA with IC50 value $20 \mathrm{mM}$ VPA, while BHY is the most sensitive one IC50 value $2.1 \mathrm{mM}$ VPA

\begin{tabular}{lcc}
\hline Cell line & VPA IC $_{\mathbf{5 0}}$ (nM) & $\mathbf{9 5 \%} \mathbf{C l}$ \\
\hline A549 & 6.63 & $5.77-7.63$ \\
SKLU1 & 20.00 & $11.80-33.92$ \\
BHY & 2.10 & $19.40-2.27$ \\
\hline
\end{tabular}




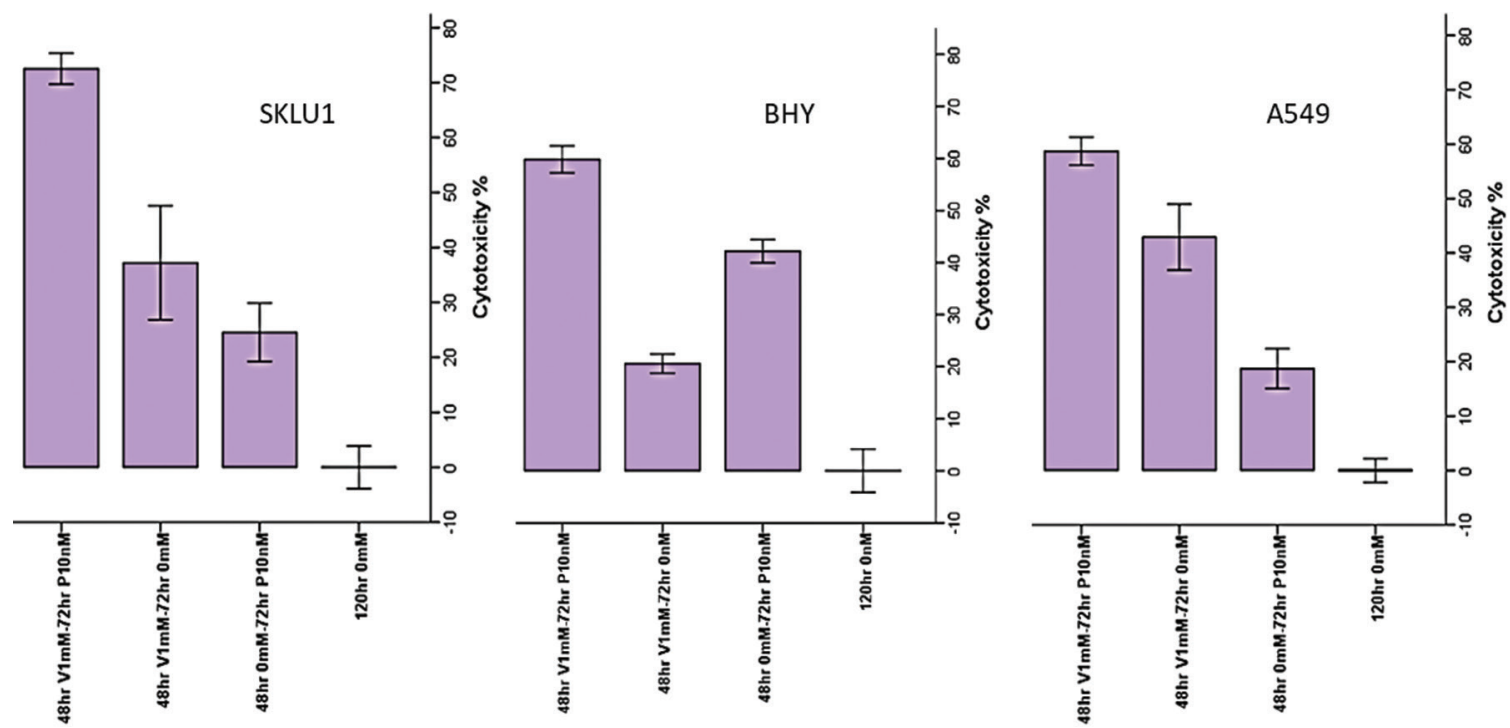

Fig. 2 Bar charts of cytotoxic effects of 48-hour treatment with $1 \mathrm{mM}$ VPA flowed by $72 \mathrm{~h}$ of $10 \mathrm{nM}$ paclitaxel on A549, BHY and SKLU1 cell lines. Interestingly, SKLU1 cell line exhibited more response to paclitaxel after $48 \mathrm{~h}$ exposure to VPA. BHY showed different trend of response to treatment of VPA and paclitaxel separately compared to A549 and SKLU1 cell lines. Error bars represent $95 \%$ confidence

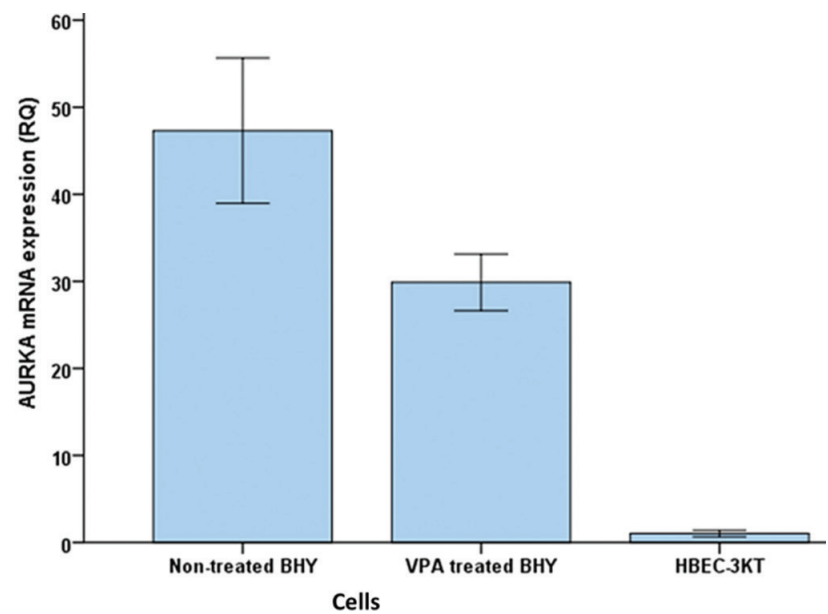

Fig. 3 AURKA mRNA expression in VPA-treated BHY cells with 1 $\mathrm{mM}$ concentration compared with non-treated in comparison with HBEC-3KT control. VPA treatment seems to reduce AURKA expression to around $65 \%$. Error bars were represented $95 \%$ confidence

Then it was examined how the status of tumour suppressor gene $p 53$ could affect the paclitaxel sensitisation of HBEC cell lines to paclitaxel. The results demonstrated that the VPA exhibited more efficiency in sensitising p53 wild type HBEC cells to paclitaxel than that exhibited in sensitising p53 knockouts and thus p53 expression seems to increase the cytotoxic effect of paclitaxel after course exposure to $0.5 \mathrm{mM} \mathrm{VPA}$ although pre-treatment of HBECs with $1 \mathrm{mM}$ VPA shows different trend (Fig. 4).

The efficiency of decitabine treatment of A549 was determined at different concentrations $(50,100$ and $200 \mu \mathrm{M})$ by measuring the global methylation levels (LINE-1 element) (Fig. 5).

This agent showed a dose-dependent efficiency to demethylate A549 cellular DNA (Fig. 6).

Although decitabine was efficient in reducing global LINE methylation, it did not sensitise any of the cell lines to paclitaxel when used either in a synchronous (Fig. 7) or in a preceding manner (data not shown).
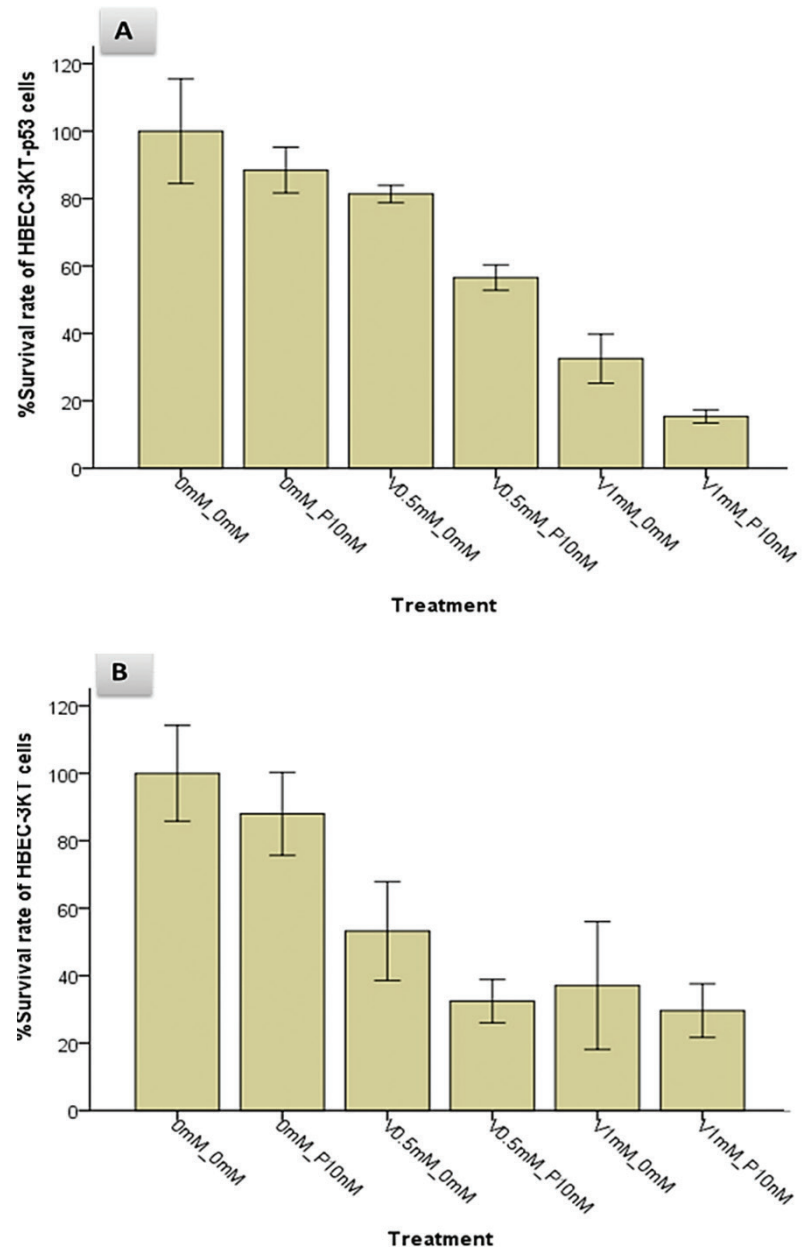

Fig. 4 Bar charts of cytotoxic effects of $48 \mathrm{~h}$ treatment with 1 and $0.5 \mathrm{mM}$ VPA followed by $72 \mathrm{~h}$ of $10 \mathrm{nM}$ paclitaxel on HBEC-3KT (A) and HBEC-3KT-p53 (B) cell lines. p53 Wild type HBEC cells showed more response to $10 \mathrm{nM}$ paclitaxel after $48 \mathrm{~h}$ exposure to 0.5 mM VPA compared with p53 knockouts. However, increasing VPA concentration to $1 \mathrm{mM}$ no more effect in HBEC-3KT as opposed to more effect in HBEC-3KT-p53. Error bars represent 95\% confidence intervals. 


\section{A}

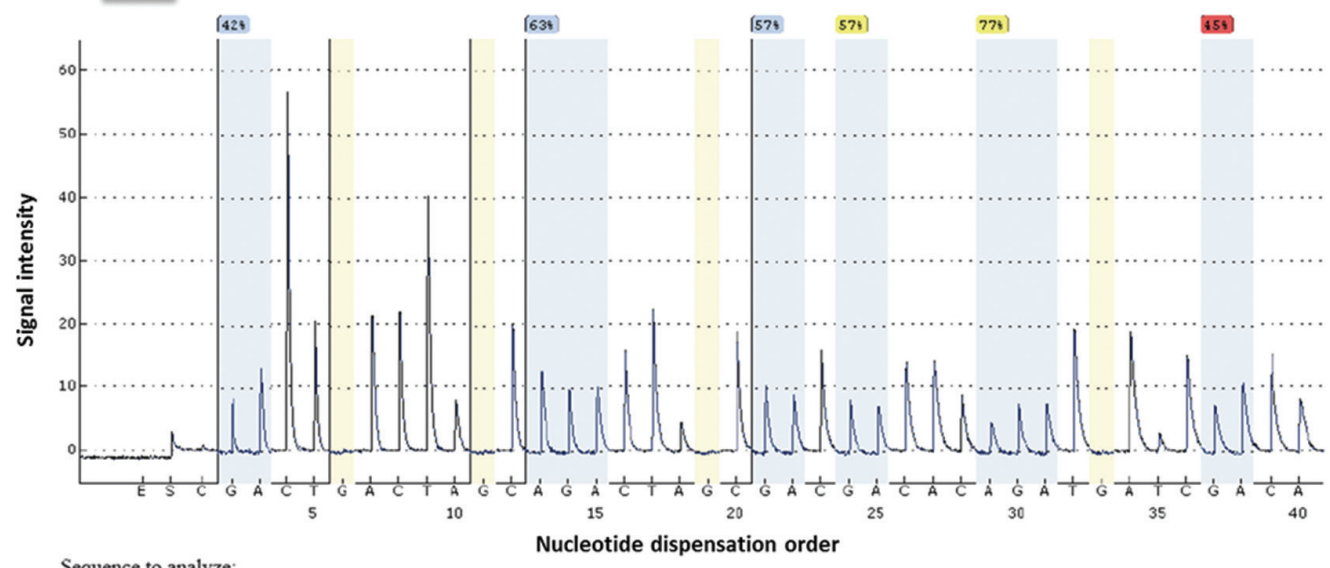

RCCCTACTTCRACTCRCRCACRATACRCACACACACTAACCTAC

B

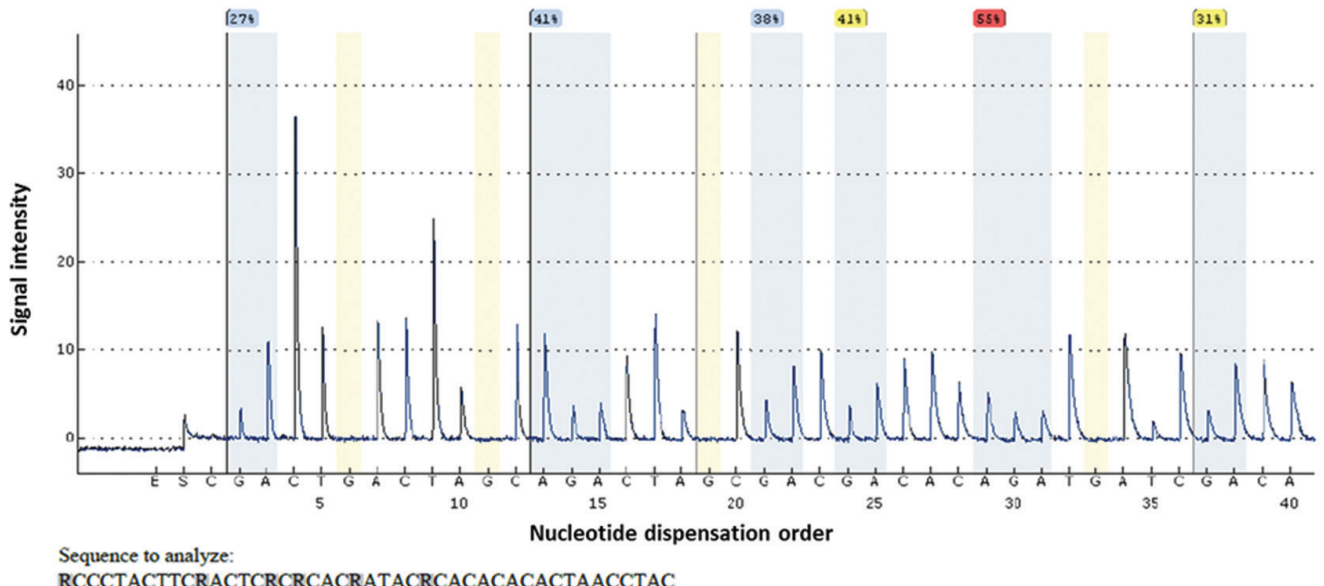

RCCCTACTTCRACTCRCRCACRATACRCACACACACTAACCTAC

Fig. 5 Pyrograms of LINE-1 global methylation analysis demonstrating the cellular DNA methylation status of A549 cell line in the absence (A) and presence (B) of decitabine at $200 \mu \mathrm{M}$.

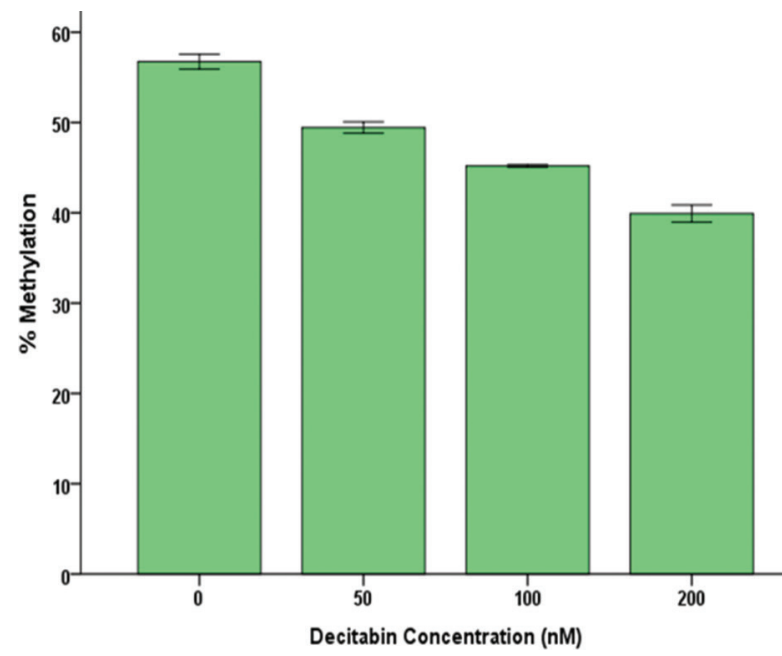

Fig. 6 The bar chart demonstrating the change in the methylation status of LINE-1 following treatment of A549 with the demethylating agent decitabine at different concentration $(0,50$, 100 and $200 \mu \mathrm{M})$. The results showed that reduction of the methylation level correlated with increasing decitabine dose.
In order to provide insight into the inability of decitabine to sensitise cell lines to paclitaxel, the methylation status of the different gene promoters tested in this study was investigated. The pyrosequencing analysis demonstrated that none of the gene promoters examined in this study demonstrated altered methylation status; in fact all promoters were unmethylated in all tumour and normal tissues tested (Fig. 8).

\section{Discussion}

The data obtained demonstrated that pre-treatment of three different RTC cell lines with VPA sensitised these cells to paclitaxel, while decitabin has no such sensitising effect. The maximum concentration that has been used in this study was corresponded to levels in the plasma of patient treated for epilepsy that ranged from 30 to $111 \mathrm{mg} / \mathrm{L}$ as opposed to $0.2-0.8$ $\mathrm{mM}$ and exhibited low risk side effects, ${ }^{11}$ while resulting in histone acetylation. ${ }^{12}$ These findings are consistent with Chen et al., ${ }^{13}$ who established that VPA enhanced paclitaxel response in resistant human lung adenocarcinoma cells but in dose-dependent manner, but in contrast to Erlich et al., ${ }^{6}$ who could 

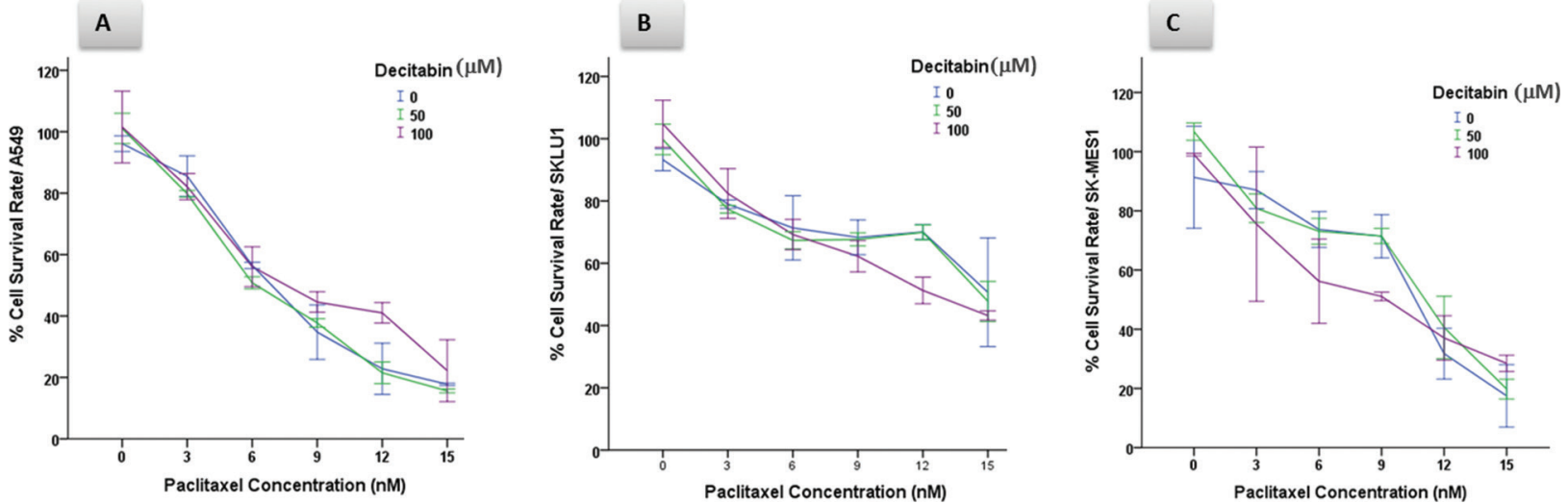

Fig. 7 MTT line graphs showing the sensitivity of A549 (A), SKLU1 (B) and (C) SKMES1 cell lines to paclitaxel in the presence of differing concentrations of decitabine $(0,50$ and $100 \mu \mathrm{M})$. The data showed no significant difference in cellular response to treatment with paclitaxel alone or in combination with decitabine. Error bars were represented $95 \%$ confidence intervals.

A

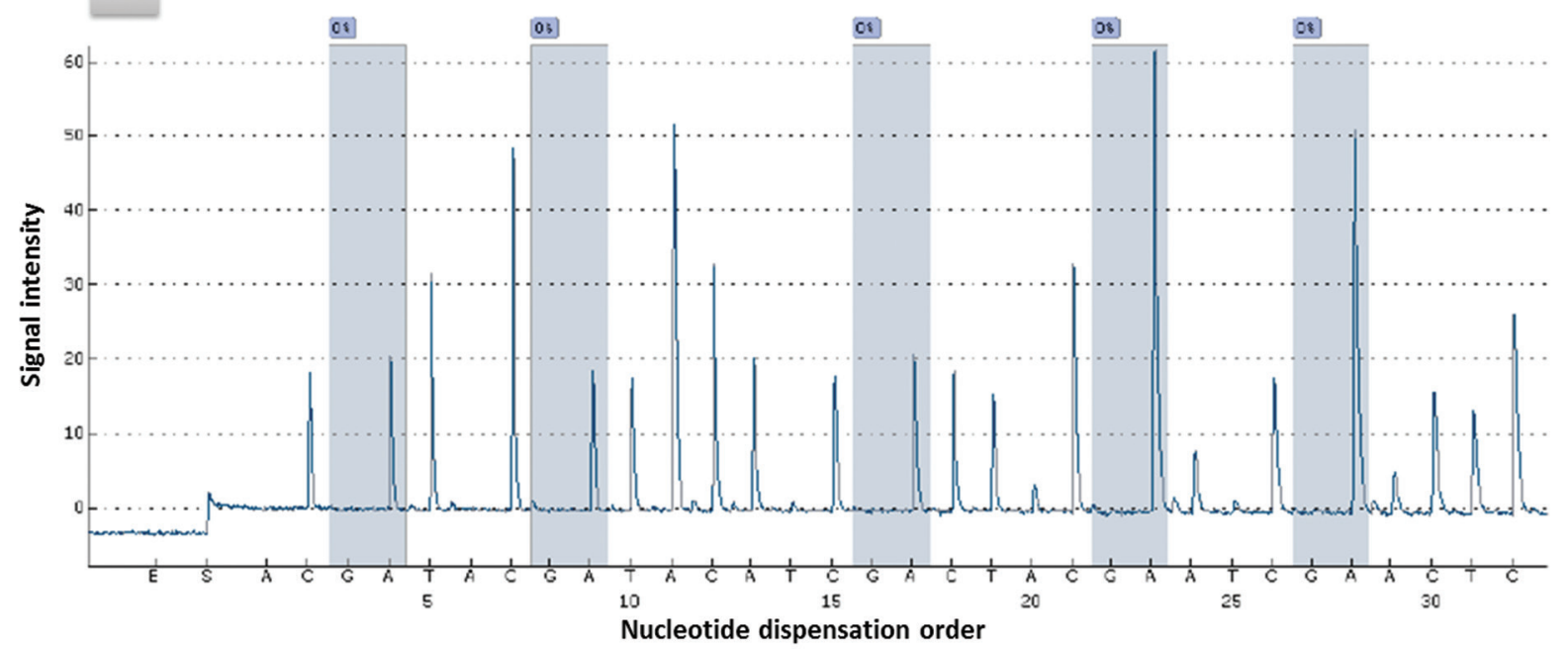

Sequence to analyze:

CRTTCCORTAAACCACRCTCCRAAAACRAAACTCCAATAAAAATACTACATCC

B

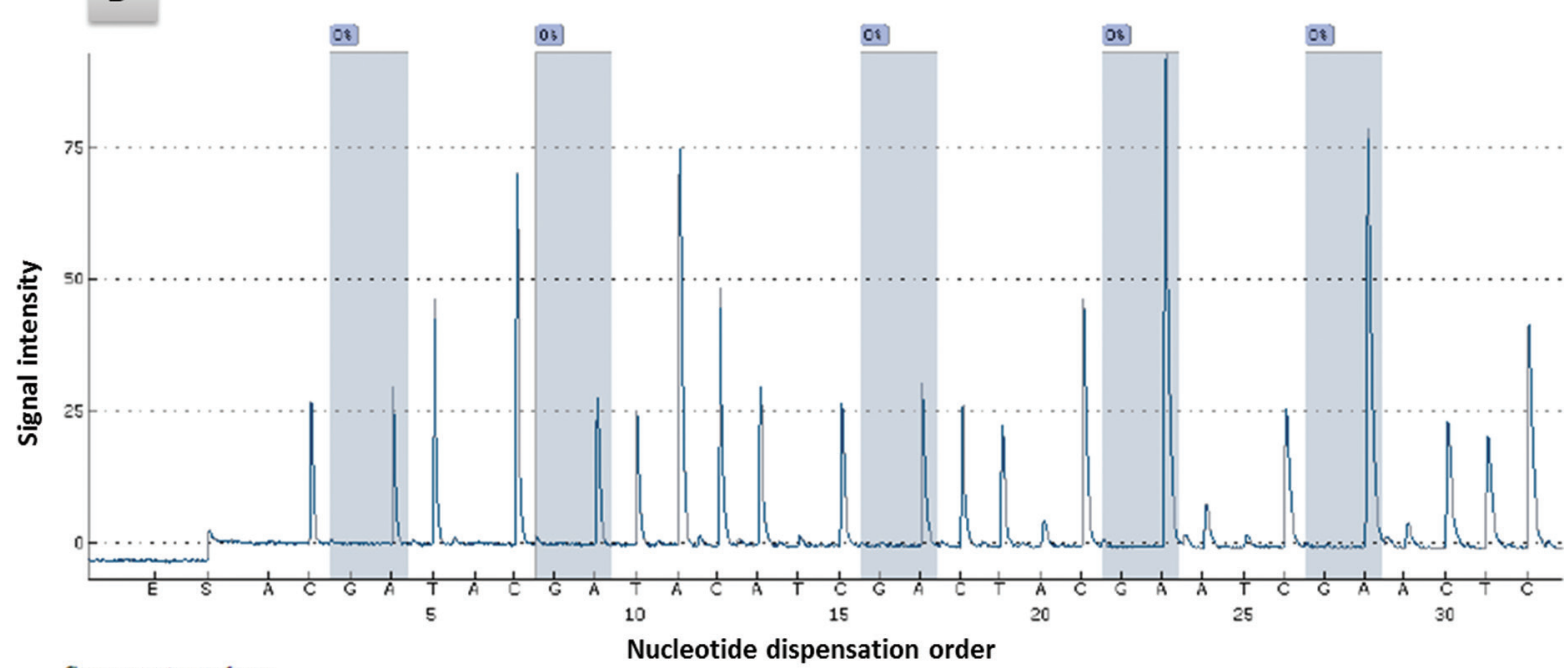

Sequence to analyze:

Nucleotide dispensation order

CRTTCCORTAAACCACRCTCCRAAAACRAAACTCCAATAAAAATACTACATCC

Fig. 8 Representative pyrograms showing DNA demethylation status of AURKA gene promoter in (A) tumour and (B) normal lung samples. The figures show that the gene promoters were unmethylated in both malignant and normal tissues of the lung. 
not deduce that VPA can potentiate the cytotoxic effect to paclitaxel in HNSCC cells. This inconsistency probably exists because the researchers did not try to pre-treat the cells with VPA prior paclitaxel treatment rather they examined only the VPA-paclitaxel combination. However, the findings demonstrated a minor effect of VPA and paclitaxel in RTC cells. This epigenetic sensitisation of cancer cells to paclitaxel might result through induction of apoptosis due to enhancement of tubulin acetylation. ${ }^{4}$ Although paclitaxel-induced apoptosis in NSCLC is well documented and p53-independent, ${ }^{14-17}$ following the finding that VPA pre-treatment potentiates paclitaxel cytotoxic effect in RTC cell lines. The association of VPA-mediated paclitaxel cytotoxicity with p53 status was also investigated. The results indicated that p53 status was a determinant of epigenetic sensitisation of HBEC cells to paclitaxel cytotoxicity. It was evident that $0.5 \mathrm{mM}$ VPA enhanced paclitaxel activity in p53 wild type HBEC cells but to a lesser extent in the p53-knockout derivatives. However, increased VPA dose to $1 \mathrm{mM}$ showed similar paclitaxel sensitising effect in both p53 wild type and p53 null cells. Further investigation is required to provide compelling evidence on the exact mechanism of p53 involvement on VPA-based sensitization of paclitaxel.

The present study also demonstrated that VPA exposure of BHY cells led to the reduction of AURKA mRNA expression. This suggests that AURKA transcription is under epigenetic control. ${ }^{18}$ While the mechanism behind VPA-mediated sensitisation to paclitaxel is still unclear, the reduction of AURKA expression may be one of the mediators due to the fact that higher levels of AURKA transcripts are associated with poor prognosis of NSCLC. ${ }^{19}$

\section{Conclusion}

In conclusion, the results indicate that HDAC inhibitors could be beneficial in sensitising RTC cells to paclitaxel, which is a very common and inexpensive chemotherapeutic agent. Such sensitisation could lead to lowering the effective dose of paclitaxel and subsequently reducing the adverse effects of this drug to the patient. Additional preclinical and clinical evidence is required to provide further support to our observation. The great advantage of VPA is that it is in routine clinical use for many years demonstrating minor side effects. Further research is required to establish the exact molecular mechanisms modulating this epigenetic sensitisation of cancer cells to paclitaxel.

\section{Acknowledgment}

This project is co-funded by the University of Baghdad and Ministry of Higher Education and Scientific Research (MOHESR)/IRAQ alongside the Roy Castle Lung Cancer Foundation, UK.

The authors would like to acknowledge Triantafillos Liloglou for critically reading the manuscript.

\section{Conflicts of interest}

None.

\section{References}

1. Braiteh F, Soriano AO, Garcia-Manero G, Hong D, Johnson MM, Silva Lde P, et al. Phase I study of epigenetic modulation with 5-azacytidine and valproic acid in patients with advanced cancers. Clin Cancer Res. 2008;14:6296-6301.

2. Chu BF, Karpenko MJ, Liu Z, Aimiuwu J, Villalona-Calero MA, Chan KK, et al. Phase I study of 5-aza-2'-deoxycytidine in combination with valproic acid in non-small-cell lung cancer. Cancer Chemother Pharmacol. 2013;71:115-121.

3. Roy Choudhury S, Karmakar S, Banik NL, Ray SK. Valproic acid induced differentiation and potentiated efficacy of taxol and nanotaxol for controlling growth of human glioblastoma LN18 and T98G cells. Neurochem Res. 2011;36:2292-2305.

4. Catalano MG, Poli R, Pugliese M, Fortunati N, Boccuzzi G. Valproic acid enhances tubulin acetylation and apoptotic activity of paclitaxel on anaplastic thyroid cancer cell lines. Endocr Relat Cancer. 2007;14:839-845.

5. Tesei A, Brigliadori G, Carloni S, Fabbri F, Ulivi P, Arienti C, et al. Organosulfur derivatives of the HDAC inhibitor valproic acid sensitize human lung cancer cell lines to apoptosis and to cisplatin cytotoxicity. J Cell Physiol. 2012;227:3389-3396

6. Erlich RB, Rickwood D, Coman WB, Saunders NA, Guminski A. Valproic acid as a therapeutic agent for head and neck squamous cell carcinomas. Cancer Chemother Pharmacol. 2009:63:381-389.

7. Bailey VJ, Easwaran H, Zhang Y, Griffiths E, Belinsky SA, Herman JG, et al. MS-qFRET: a quantum dot-based method for analysis of DNA methylation. Genome Res. 2009;19:1455-1461.

8. Kim CH. Druggable targets of squamous cell lung cancer. Tuberc Respir Dis (Seoul). 2013;75:231-235.

9. Timofeeva MN, Hung RJ, Rafnar T, Christiani DC, Field JK, Bickeböller H, et al. Influence of common genetic variation on lung cancer risk: meta-analysis of 14900 cases and 29485 controls. Hum Mol Genet. 2012;21:4980-4995.

10. Jones SE, Erban J, Overmoyer B, Budd GT, Hutchins L, Lower E, et al. Randomized phase III study of docetaxel compared with paclitaxel in metastatic breast cancer. J Clin Oncol. 2005;23:5542-5551.
11. Zighetti ML, Fontana G, Lussana F, Chiesa V, Vignoli A, Canevini MP, et al. Effects of chronic administration of valproic acid to epileptic patients on coagulation tests and primary hemostasis1. Epilepsia. 2015;56: e49-e52.

12. Tremolizzo L, Difrancesco JC, Rodriguez-Menendez V, Riva C, Conti E, Galimberti G, et al. Valproate induces epigenetic modifications in lymphomonocytes from epileptic patients. Prog Neuropsychopharmacol Biol Psychiatry. 2012;39:47-51.

13. Chen J, Liu J. Spatial-temporal model for silencing of the mitotic spindle assembly checkpoint. Nat Commun. 2014;5:4795.

14. King TC, Akerley W, Fan AC, Moore T, Mangray S, Hsiu Chen M, et al. p53 mutations do not predict response to paclitaxel in metastatic nonsmall cell lung carcinoma. Cancer 2000;89:769-773.

15. Vogt U, Zaczek A, Klinke F, Granetzny A, Bielawski K, Falkiewicz B. p53 Gene status in relation to ex vivo chemosensitivity of non-small cell lung cancer. J Cancer Res Clin Oncol. 2002;128:141-147.

16. Das GC, Holiday D, Gallardo R, Haas C. Taxol-induced cell cycle arrest and apoptosis: dose-response relationship in lung cancer cells of different wildtype p53 status and under isogenic condition. Cancer Lett. 2001;165:147153

17. Duarte ML, de Moraes E, Pontes E, Schluckebier L, de Moraes JL, Hainaut $P$, et al. Role of p53 in the induction of cyclooxygenase-2 by cisplatin or paclitaxel in non-small cell lung cancer cell lines. Cancer Lett. 2009;279:5764.

18. Zhang XH, Rao M, Loprieato JA, Hong JA, Zhao M, Chen GZ, et al. Aurora $A$, Aurora $B$ and survivin are novel targets of transcriptional regulation by histone deacetylase inhibitors in non-small cell lung cancer. Cancer Biol Ther. 2008:7:1388-1397.

19. Al-Khafaji ASK, Marcus MW, Davies MPA, Risk JM, Shaw RJ, Field JK, et al. AURKA mRNA expression is an independent predictor of poor prognosis in patients with non-small cell lung cancer. Oncol Lett. 2017;13: 4463-4468. 